school kept up so much better than in the girls', yet in the end nearly as large a proportion of boys was attacked as girls. At the large schools in Chelmsford exactly the contrary was experienced; 60 per cent. of the 200 boys suffered, 33 per cent. of the 164 girls, and 40 per cent. of the 150 infants. At Danbury 60 per cent. of the children under nine years and only 40 per cent. of those over that age were attacked. At Latchingdon 50 per cent. of the elder children and only 30 per cent. of the infants were affected. At Runwell the influence of the epidemic was only felt by such of the elder children as came from a particular district. At Great Waltham the boys and girls suffered about equally, but the infection seemed to have spread more rapidly amongst the boys. The infants are said not to have been attacked until a week later than the elder children, but the epidemic more rapidly attained its acme here than in either of the other departments. In many schools no after-effects have been observed. Other teachers probably more observant noted "general weariness and lack of interest," "languid appearance," "chronic laxity," "pallor and low spirits," "greater susceptibility to colds," "coughs and bronchitis," "sores about face and body," \&c. All the teachers with whom I have conversed assert that the children when they returned to school were very restless, and quite incapable of fixing the attention upon any subject, making teaching for some weeks a most disheartening task.

Effects upon the death-rate amongst children in the rural districts.-During the past three months the death-rate has been abnormally high, whe excess being entirely due to the mortality from whooping-cough and lung affections.

Total Deaths of Children under fifteen in Chelmsford and Maldon Rural Districts for the three months ending March 31st, 1839.

\begin{tabular}{|c|c|c|c|c|c|c|c|c|c|}
\hline & & & $\begin{array}{l}\text { year } \\
\text { unde }\end{array}$ & & $\begin{array}{l}\mathbf{1} \text { to } 5 \\
\text { years. }\end{array}$ & & $\begin{array}{l}5 \text { to } 15 \\
\text { years. }\end{array}$ & & Total \\
\hline Whooping-cough & $\cdots$ & $\ldots$ & 8 & $\ldots$ & 12 & $\ldots$ & 2 & . . & 22 \\
\hline Croup... ... ... & $\cdots$ & $\ldots$ & 一 & $\ldots$ & - & $\ldots$ & 1 & . & 1 \\
\hline Diphtheria & $\ldots$ & $\ldots$ & - & $\ldots$ & 1 & $\ldots$ & 1 & • & 2 \\
\hline Influenza... & $\ldots$ & $\ldots$ & 1 & $\ldots$ & 1 & $\ldots$ & $\hat{1}$ & $\ldots$ & 3 \\
\hline Bronchitis \&c.... & $\ldots$ & $\ldots$ & 13 & $\ldots$ & 9 & $\ldots$ & 4 & $\cdots$ & 26 \\
\hline All other diseases & $\ldots$ & $\ldots$ & 18 & $\ldots$ & 7 & $\ldots$ & 1 & $\ldots$ & 26 \\
\hline Totals ... & $\ldots$ & .. & 40 & $\ldots$ & 30 & .. & 10 & $\ldots$ & 80 \\
\hline
\end{tabular}

During the year 1889 the deaths among children were distributed as under:

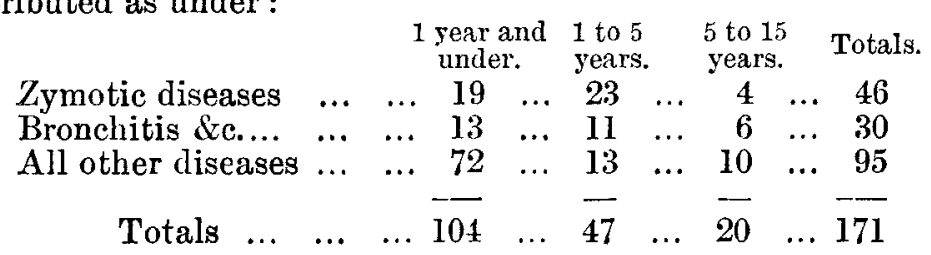

That the mortality amongst children has been excessive during the past three months is obvious. The deaths from lung diseases for the quarter are almost as numerous as the total for the whole of the past year.

At the last census the proportion of children under fifteen years of age to each 1000 of population was in my districts 395 , and as the total population is in round numbers 42,000 we have at last 16,000 children. Fully half of these, I believe, suffered from the influenza. As only three deaths have been attributed to the direct effect of the disease, the mortality would be about 4 per 10,000 cases. If, on the other hand, we attribute the whole of the excessive mortality to the indirect effect, the deaths would number 4.5 per 1000 cases.

In conclusion, we may ask, Do any of the facts I have recorded help us in forming an opinion as to the origin and mode of propagation of the disease? Would its dissemination by contagion only account for its appearance in twenty live parishes in the same week? To do so we must assume a very high degree of infectivity. The rapidity with which the epidemic spread in some of the schools, causing them to be closed for lack of scholars within a week of its first appearance, might be explained on some such hypothesis ; but, on the other hand, the small number of children affected in other schools in which well-marked cases occurred indicates so slight a degree of infectivity that we may well doubt whether it is at all contagious. The very varied manner in which the schools were affected by the epidemic would necessitate our also having to assume that the susceptibility of children in different localities varied in a most extrsordinary manner. Whether contagious or not, how can we account for the fact that in many parishes the adults suffered so much more, both in point of numbers and in severity, than the children, whilst in the majority of distriats quite as large a proportion of children were attacked ? What had caused the diminished susceptibility in certain areas? At Pleshey, for instance, was it the prior epidemic of November? And was this an epidemic of the same disease as that which subsequently returned, to affect only the adult population, the children having been rendered nonsusceptible by the previous visit? Is it possible that some almost universally diffused organism has, under changed conditions, the extent of that change varying in different localities, acquired more or less rapidly a disease-producing virulency which normally it does not possess? As succeeding generations increased in activity in those areas where the development was comparatively slow and gradual, the children being more susceptible, would be first affected, and the disease being mild in form and indefinite in character, would escape recognition as influenza, but possibly confer some slight degree of immunity from subsequent attack when the virus had increased in potency. In other cases where development was more rapid, the children again, as at Pleshey, might be first affected, and the symptoms be such as to indicate the closest resemblance to the fully developed disease. In such a case we should also expect the children to escape when the disease at a later period assumed a more virulent type, which is exactly what did occur. In the other distriet the conditions favourable to the rapid development of the virulency of the organism existed in such a high degree that young and old became almost at the same time susceptible to its influence.

As to what the conditions above referred to are, if they exist, we are at present profoundly ignorant, but we must assume that they are abnormal and temporary; hence, after a period which may vary in different places, the organism would more or less rapidly revert to its original condition. This process of attenuation and the diminished number of susceptible individuals - diminished both on account of the decreased activity of the virus and the partial immunity conferred by an attack of the disease-would account for the gradual disappearance of the epidemic. With reference to the incubation period I dare not at present even offer an opinion. It has been asserted that, given a short incubation period and a very high degree of infectivity and susceptibility, everything in connexion with the epidemic could be accounted for. My investigations have led me to exactly the opposite conclusion. The theory I have just had the temerity to propound seems to me to explain much more satisfactorily the many varied and often apparently contradictory facts which I have observed. Whether it can as readily explain the observations of others $I$ am not at present prepared to discuss.

Chelmsford.

\section{THE INFLUENZA EPIDEMIC AT THE STATE CRIMINAL LUNATIC ASYLUM, BROAD. MOOR, BERKS.}

BY REGINALD H. NOOTT, M.B. EDIN., ASSISTANT MEDICAL OFFICER.

THE following brief notes, contributed by permission of the Superintendent, refer to the influenza epidemic as observed among the patients, the staff, and others connected with the above institution during the first four months of the present year.

The first case was observed on Jan. 8th, the last case on May 3rd, the epidemic reaching its height about Feb. 14th. During this time 206 individuals were attacked, of whom 176 were over eighteen years of age and 30 under; of these latter 24 were under twelve years of age, and of the 176 adults 141 were males and 35 females of 416 male patients 74 were affected, or 17.7 per cent.; of $15 \mathrm{~L}$ female patients 20 were affected, or 132 per cent.; of 84 male attendants 46 were affected, or 54.7 per cent.; of 34 female attendants 11 were affected, or 323 per cent. This accounts for $15 \mathrm{l}$ out of the total number, 206 ; the remaining 55 occurred in the families of members of the staff, and among those members of the staff who are not attendants. The average time during which the 46 male attendants were absent from duty was 11.2 days; the longest absence being 21 days and the shortest 6 days. It was noticeable that the length of absence from duty was in direct ratio to the age of the 
patient. The average time during which the 11 female lungs. The temperature of the patient in each case was" attendants were absent from duty was 122 days; the longest absence being 21 days and the shortest 7 . The cases were on the whole simple in their character and free from complication. The onset of the attack, as a rule, was sudden, the most prominent symptoms being fever, acute frontal headache, muscular pains-which were most severe and lasted longest across the loins-great mental depression, and anorexia. The temperature ranged from $102^{\circ}$ to $103^{\circ}$ as a rule; in a few cases it rose to $104^{\circ}$. In some cases among the inmates of the asylum the mental depression was so great as to become melancholia, and in one case there resulted a condition of complete mental torpor which lasted four weeks. 'Two cases showed severe gastric symptoms with persistent vomiting for nearly twenty-four hours. It was noticeable that any constitutional or acquired weakness was brought out by the malady: for instance, in patients with any pneumonic weakness the bronchial catarrh was much more severe than in others; in patients subject to rheumatism the muscular pains were more severe and lasted longer; in one patient, aged sixteen, who five years previously had suffered from brain fever, there was acute delirium during the fever stage of the disease. A child aged two years and a half, who had on several previous occasions suffered from oplthalmia, developed purulent ophthalmia which gave a considerable amount of trouble. Catarrhal symptoms, more particularly discharge from the eyes and nose, were present in only a small number of cases. The general treatment adopted was the adninistration of diaphoretics during the early stage of the disease, followed by quinine, bark, \&c., during convalescence, any special symptoms being treated on the ordinary lines.

Three cases among the inmates of the asylum had a relapse and developed pneumonia, which proved fatal in each case. The following are short notes of these cases with the post-mortem appearances:

CASE 1.-W. M-This patient went to bed with influenza on Feb. 5th, He was allowed up in the day-room on Feb. 12th. He was sent to bed again suffering from pneumonia and pleurisy on Feb. 15th, and died on Feb. 19th. At the necropsy, the right pleura was found to be thickened throughout and covered with a thick layer of lymph. The left pleura was normal. There was no fluid in either pleural cavity. The lower lobes and lower half of the upper lobe of the right lung were consolidated, and in an advanced state of grey hepatisation. The lower lobe of the left lung was consolidated, and in a state of red hepatisation. The weight of the right lung was $55_{4}^{\frac{1}{4}} \mathrm{OZ}$, the left lung weighing $3 \frac{1}{4} \mathrm{oz}$.

CASE 2.-P. J-. This patient went to bed with influenza on Feb. 5th. He was allowed up in the day-room on Feb. 12th. He was sent to bed, suffering from pneumonia and pleurisy, on Feb. 15th, and died on Feb. 20 th. At the necropsy, the left pleura was found to be thickened throughout and covered with a thick layer of lymph. The left pleural cavity contained about $30 \mathrm{oz}$. of straw-coloured fluid. The right pleura was slightly opaque. The left lung was consolidated throughout with the exception of a small portion at the apex, and was in an advanced state of grey hepatisation. The lower two lobes of the right lung were consolidated, the lower half being in a state of grey hepatisation, the upper half showing red hepatisation, while the inflammation was just beginning to attack the lower part of the upper lobe. The right lung weighed $28 \frac{1}{2} \mathrm{oz}$, the left lung $56 \mathrm{oz}$.

CASE 3.-J. S-. This patient went to bed with influenza on Feb. 7th; he was allored up in the day-room on Feb. 11th. The weather being mild, he was allowed outdoor exercise on Feb. 18th. He had to take to his bed again suffering from pneumonia and pleurisy on Feb. 2 lst, and died on March lst. At the necropsy the left pleura showed old adhesions and recent inflanmation anteriorly. The left lung was consolidated throughout, and in an advanced state of grey hepatisation. The right lung was congested and odematous; it weighed $33 \frac{3}{\mathrm{az}}$; ; the left $78 \frac{3}{1} \mathrm{oz}$. This last case differs somewhat from the other two, as the patient took out-door exercise on three days, whereas the other two patients did not go into the open air from the time they were first attacked; and it may here be stated that the rooms they occupied, as well as the corridors along which they had to pass to the day room, were efficiently heated with hot air, so that there was no chance of their being exposed to cold during convalescence. The pneumonia from which these three patients suffered was of a very severe type, affecting large portions of the different from the typical pneumonic temperature, being very irregular, and sometimes higher in the morniog than in the evening, while a few hours previously to death it was subnormal.

These were the only fatal cases. The clinical history and post-mortem appearances in these cases support the idea that the pneumonia from which these patients suffered was: different from ordinary pneumonia; that it was a pneumonia modified in some way by the presence of the influenza: poison; and it seems probable that the inflammatory process is due to the extension of the action of the poison down. the bronchial tubes to the air vesicles. From the fact that two of the patients did not go into the open air and were not otherwise exposed to cold, it would seem that this may? take place even though the patients be placed under the most favourable circumstances, though no doubt exposure to cold would act as a predisposing cause. Four individuals had two distinct attacks, the conrse of the second attack being in each case exactly similar to the first, the symptoms perhaps being rather more severe.

With regard to the epidemic generally, it was noticed that it attacked adults nuch more than children, that as a rule the older the patient the more severe were the symptoms, that the period of convalescence was much shorter in children than in adults, and that in the case of infants the indisposition was so transient that the fact that the child had influenza at all was very likely to be overlooked. The spread of the epidemic was very irregular, isolated cases appearing suddenly in cottages and in parts of the asylum far removed from one another. The following fact also bears upon the question of infection. One of eight patients occupying a dormitory contracted influenza; a tew days later another case appeared in another part of the same block. This patient. was brought to the dormitory above mentioned, and one of the original occupants took his place; as other fresh cases appeared in different parts of the block they were brought down to this dormitory, until all the other former occupants had been removed to make room for them, and yet, with the exception of the first case, not one of the original occupants of the dormitory was attacked. It was the exception for more than one member of the attendants' families to be attacked, and although thirty-five of the forty-six attendants who had it were married, the wife was attacked only in five cases.

With regard to the question, "Is Influenza infectious ?" the above evidence seems to support the theory that it is noi directly infectious-that is to say, a patient suffering from influenza cannot directly infect others around him, as a patient suffering from measles can. In the case of measles, the poison multiplies in the body of the patient, and the germs of the disease become fully developed and ripe in the body; in the case of influenza, it would seem probable that, although the poison multiplies in the body of the patient (most likely in the mucous membrane of the air passages), the germs of the disease do not become ripe in the body, but are given off into the air, where they become fully developed and infective.

Broadnoor, Berks.

\section{THE RADICAL CURE OF HERNIA.}

WITH DESCRIPTION OF A NEW MODIFICATION OF MACEWEN'S OPERATION.

BY E. STANMORE BISHOP, F.R.C.S. ENG.,

HONORARY SURGEON TO THE ANCOATS HOSPITAL, MANCHESTER. (Concluded from $p .1170$. )

THE second class of operations are those of which Macewen may be taken as a type, and includes the procedures of Barker, Macewen, and a modification of the latter which $\mathbb{I}$ have devised.

In 1886 a paper, which appeared in the Annals of Surgery for that year, by Macewen, practically marked a new era in the radical cure of hernia, and introduced a new principle, which may be stated thus: The proper block to the redescent of a hernia is the entire sac, if properly treated. Almost always present, it bears a distinct relation to the size and age of the aperture through which it has been protruded. If the opening is large, so is the sac, and correspondingly tough and resistant. But, in order to obtain its legitimate effect, it must act no longer in the canal, which it will only tend to widen, acting like a wedge, driven 